\title{
Per cent emphysema is associated with respiratory and lung cancer mortality in the general population: a cohort study
}

\author{
Elizabeth C Oelsner, ${ }^{1,2}$ J Jeffrey Carr, ${ }^{3}$ Paul L Enright, ${ }^{4}$ Eric A Hoffman, ${ }^{5}$ Aaron R Folsom, ${ }^{6}$ \\ Steven M Kawut, ${ }^{7}$ Richard A Kronmal, ${ }^{8}$ David J Lederer, ${ }^{1}$ Joao A C Lima, ${ }^{9}$ Gina S Lovasi, ${ }^{2}$ \\ Benjamin M Smith, ${ }^{1,10}$ Steven J Shea, ${ }^{1,2}$ R Graham Barr ${ }^{1,2}$
}

\begin{abstract}
- Additional material is published online only. To view please visit the journal online (http://dx.doi.org/10.1136/ thoraxjnl-2015-207822).
\end{abstract}

For numbered affiliations see end of article.

\section{Correspondence to} Dr Elizabeth C Oelsner, Department of Medicine, Columbia University, 622 West 168th Street, PH 9E-105, New York, NY 10032, USA; Eco7@cumc.columbia.edu

Received 10 September 2015 Revised 17 February 2016 Accepted 2 March 2016

Published Online First

5 April 2016

\section{SLinked}

- http://dx.doi.org/10.1136/ thoraxjnl-2016-208572

\section{CrossMark}

To cite: Oelsner EC, Carr JJ, Enright PL, et al. Thorax 2016;71:624-632

\section{ABSTRACT}

Background Emphysema on CT is a risk factor for allcause mortality in persons with and without airflow obstruction; however, causes of death associated with emphysema remain uncertain, particularly in the general population.

Aims To test associations between quantitatively assessed emphysema on CT and cause of death in persons with and without a substantial smoking history. Methods The Multi-Ethnic Study of Atherosclerosis recruited 6814 participants, aged 45-84 years and without clinical cardiovascular disease, in 2000-2002. Per cent emphysema was defined on cardiac CT as per cent of lung voxels less than -950 Hounsfield units; emphysema on CT was defined as per cent emphysema above the upper limit of normal. Cause of death was classified by administrative codes. Proportional-hazards models were adjusted for age, race/ethnicity, gender, body mass index, smoking status, pack-years, coronary artery calcium, site and education. Additional adjustment for lung function was made in a subset with spirometry from 2004 to 2006.

Results There were 1091 deaths over 12 years median follow-up. Emphysema on CT was strongly associated with increased mortality due to respiratory diseases (adjusted HR 2.94, 95\% Cl 1.68 to 5.15), particularly chronic lower respiratory diseases (adjusted HR 9.54, $95 \% \mathrm{Cl} 4.70$ to 19.35), and lung cancer (adjusted HR $1.84,95 \% \mathrm{Cl} 1.09$ to 3.12 ), but not cardiovascular disease. Associations persisted among participants with fewer than 10 pack-years and those without physiciandiagnosed respiratory disease, and were similar after adjustment for airflow measures and in persons without airflow limitation.

Conclusions Quantitatively assessed emphysema on $\mathrm{CT}$ is associated with greater respiratory disease and lung cancer mortality, even among persons without traditional risk factors.

\section{INTRODUCTION}

Pulmonary emphysema is a common 'incidental' finding on CT, occurring in $29 \%$ of smokers undergoing lung cancer screening, ${ }^{1-3}$ and $4 \%$ of healthy adults undergoing cardiac scanning. ${ }^{4}$ Emphysema is defined anatomically as destruction of lung parenchyma and loss of alveolar walls, ${ }^{5}$ a definition distinct from that of COPD, which is defined by

\section{Key messages}

What is the key question?

Is increased pulmonary emphysema on CT associated with increased risks of respiratory and lung cancer mortality in the general population?

\section{What is the bottom line?}

The results show that per cent emphysema on CT greater than the upper limit of normal, as defined by reference equations, was associated with 2-fold to 10 -fold higher rates of mortality from chronic lower respiratory disease and lung cancer in the general population, without evidence for substantial effect modification by smoking history or the presence or absence of airflow limitation on spirometry.

\section{Why read on?}

This study describes the prognostic significance of emphysema assessed quantitatively on CT in the general population and supports the conclusion that emphysema may be clinically relevant among persons not traditionally considered at high risk of mortality due to chronic lower respiratory disease or lung cancer.

airflow obstruction on spirometry that does not fully reverse with bronchodilators. ${ }^{6}$ Emphysema is common in the absence of COPD and, conversely, approximately half of patients with COPD do not

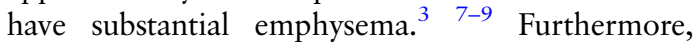
although emphysema is especially common in smokers, autopsy studies demonstrate that $10 \%$ or more of never-smokers have some degree of emphysema. $^{10}$

Important prognostic implications of emphysema have been demonstrated in high-risk populations selected for lung cancer screening trials, independent of the airflow measures that define COPD. Visual CT emphysema scores improve prediction of lung cancer mortality and are associated positively with COPD deaths and all-cause mortality; ${ }^{71-13}$ associations of these outcomes with quantitative emphysema measures have been conflicting. ${ }^{14}$

In the general population, the clinical significance of emphysema remains inadequately 
characterised. Prior studies have been restricted to smokers with 10 or more pack-years, a group that comprises only $30 \%$ of the general population of older adults; ${ }^{15}$ studies in never-smokers and ever-smokers with less than 10 pack-years remain infrequent, despite declining rates of current smoking and apparent shifts to low-smoking habits across diverse demographic groups. ${ }^{16}{ }^{17}$ We recently demonstrated that extent of emphysema-like lung (hereafter referred to as per cent emphysema) on CT was associated with all-cause mortality in a population-based sample without airflow obstruction or COPD. ${ }^{18}$ Power, however, was inadequate to address cause of death or to examine associations stratified by smoking history.

Therefore, we now report the associations between per cent emphysema and mortality due to respiratory diseases and lung cancer over 12 years of follow-up, in participants with and without substantial smoking histories, clinical lung disease or airflow limitation, in order to elucidate the risk of emphysema in the general population.

\section{METHODS}

\section{Participants}

The Multi-Ethnic Study of Atherosclerosis (MESA) enrolled 6814 participants, aged 45-84 years, who self-reported white, African-American, Hispanic or Asian race/ethnicity in 20002002. ${ }^{19}$ Exclusion criteria were history of clinical cardiovascular disease, weight $>136$ kilograms and impediments to long-term participation. Thirty participants were excluded for missing data (see online supplementary figure E1).

\section{Cause of death}

Interviewers contacted participants or family members at intervals of 9-12 months, and the National Death Index (NDI) was reviewed to assure complete follow-up for mortality through 31 December 2013. Cause-specific mortality end points were defined according to the International Classification of Diseases (ICD)-10 codes for underlying cause of death, as assigned by state vital statistics offices from the death certificate. ${ }^{20}$ This approach was blinded to participant characteristics and consistent with population-based mortality surveillance and prior respiratory outcomes studies. ${ }^{721}$

Main study end points were mortality due to respiratory diseases (J00-J99), lung cancer (C33-C34) and, combining these, all lung diseases. We specifically examined mortality due to chronic lower respiratory diseases (CLRD), defined as deaths with COPD, emphysema, chronic bronchitis or asthma (J40-47) as the underlying cause, or, in the context of pneumonia (J1218 ) as the underlying cause, CLRD as a contributing cause.

Death certificates were available for 33 of 39 CLRD deaths $(85 \%)$, family narratives were additionally available for $3(8 \%)$ and discharge summaries for in-hospital deaths were available for $11(28 \%)$. These records were independently reviewed by two physicians (ECO, RGB) to confirm CLRD as the underlying cause of death according to the WHO definition. ${ }^{20}$ Both reviewers classified CLRD as the underlying cause of death in $100 \%$ of available records. In one case, available records were ambiguous regarding whether CLRD predominated in causing fatal pneumonia, although CLRD was favoured by both reviewers. All cases were retained for the main analyses.

Cardiovascular deaths adjudicated by MESA were examined as a secondary end point.

\section{Emphysema}

MESA participants underwent cardiac CT in 2000-2002 using standardised protocols on either electron-beam or multidetector
CT. ${ }^{22}$ For each participant, two scans were performed at suspended full inspiration from the carina to the lung bases with transverse fields-of-view that captured the whole lung field. Scans captured on average $65 \%$ of the total lung volume. ${ }^{23}$

Image attenuation was assessed using a modified version of the Pulmonary Analysis Software Suite at a single reading centre by trained readers blinded to other participant information. Per cent emphysema was defined as the percentage of lung voxels with attenuation less than -950 Hounsfield units $(\mathrm{HU})$ on the scan with higher air volume or, in the case of discordant quality scores, the higher quality scan.

Emphysema on CT was defined as per cent emphysema greater than the upper limit of normal, defined by MESA reference equations. ${ }^{24}$

Per cent emphysema was also calculated for upper-lobe and basilar regions, which were defined as the cephalad eighth and caudal third of the imaged lung, respectively. The area of lung with features suggestive of interstitial lung disease (ILD), hereafter referred to as high attenuation areas (HAA), was defined as volume of lung voxels with attenuation between -600 and $-250 \mathrm{HU} .{ }^{25}$ These measures were previously validated against those obtained from full-lung scans in MESA. ${ }^{23} 25$

\section{Spirometry}

Spirometry was attempted in 2004-2006 for 3965 participants with baseline measurements of endothelial function, consent for genetic analyses and an examination during the MESA Lung Study recruitment period (see online supplementary figure E1). A total of 3847 participants performed manoeuvres in accordance with the American Thoracic Society/European Respiratory Society (ATS/ERS) guidelines on a dry rolling seal spirometer (Occupational Marketing); ${ }^{26}$ results were reviewed by a single investigator. Restriction on spirometry was classified as FVC $<80 \%$ predicted with ratio of $\mathrm{FEV}_{1}$ to $\mathrm{FVC}>0.7$. $^{6}$

\section{Covariates}

Age, sex, race/ethnicity, educational attainment, physiciandiagnosed emphysema and asthma and tobacco use were selfreported at baseline. Never smoking was defined as a lifetime smoking history of less than 100 cigarettes, and current smoking as cigarette use within the past 30 days. Urinary cotinine was measured for a subset of 3929 participants; 78 participants $(2 \%)$ who denied current smoking, but had urinary cotinine levels $>100 \mathrm{ng} / \mathrm{mL}$ were reclassified as current-smokers. Pack-years were calculated as (cigarettes per day/20) $\times$ years smoked.

Height and weight were measured using standard techniques, and body mass index (BMI) was calculated as kilogram/ metre-squared. Phantom-adjusted coronary artery calcium Agatston scores were calculated from each cardiac CT and the mean of the two values was used. ${ }^{27}$

\section{Statistical analysis}

Cause-specific mortality rates were computed per 10000 person-years of observation. Survival time was calculated as age at death or, for non-deceased participants, age at last follow-up or the most recent NDI update, whichever was more recent, with left truncation at age of study entry or, in analyses incorporating airflow measures, age at spirometry; survival time since enrolment was used in secondary analyses. For analyses regarding specific cause of death (eg, lung cancer), participants dying from other causes (eg, CLRD) were treated as censored. The proportional-hazards assumption was confirmed via interaction terms with time $(p>0.10)$. 
HRs were reported for presence of emphysema on CT, as defined above. Since the distributions of continuous emphysema exposures were left-skewed, HRs were reported per IQR. Analyses were adjusted for potential confounders and precision variables defined a priori based on prior literature: baseline age, sex, race/ethnicity, BMI, educational attainment, smoking status, pack-years and Agatston score. The standard model was more parsimonious than in a prior publication given the smaller number of events in the present paper and the lack of appreciable confounding by these other factors, assessed by impact of sequential adjustment on the HR. ${ }^{18}$ In the subset with spirometry, the standard model was additionally adjusted for the $\mathrm{FEV}_{1}$, $\mathrm{FEV}_{1} / \mathrm{FVC}$ ratio and restriction on spirometry. To account for potential confounding by subclinical ILD, models were further adjusted for HAA.

Analyses were stratified by smoking history, baseline physician-diagnosed CLRD and airflow limitation on study spirometry, defined as an $\mathrm{FEV}_{1} / \mathrm{FVC}$ ratio $<0.70,{ }^{6}$ and multiplicative interaction terms were tested in fully adjusted models.

Associations were compared with those for cardiovascular and non-lung cancer mortality, and also with effect estimates obtained from models treating cardiovascular and non-lung cancer mortality as competing risks.

Statistical analyses were performed using SAS V. 9.3 (Cary, North Carolina, USA) or R V. 3.0.2 (Vienna, Austria).

\section{RESULTS}

The 6784 participants in the primary analyses (see online supplementary figure E1) had a mean age at CT scanning of 62 years, were $38.5 \%$ white, $27.7 \%$ African-American, $22.0 \%$ Hispanic and $11.8 \%$ Asian, and included 14.2\% current-smokers, $40.5 \%$ former-smokers and $45.3 \%$ neversmokers. The median value for per cent emphysema was $2.9 \%$, with an IQR of $4.5 \%(1.2-5.7 \%)$. Per cent emphysema was modestly inversely correlated with $\mathrm{FEV}_{1} / \mathrm{FVC}$ ratio $(\mathrm{r}=-0.37)$ and HAA $(\mathrm{r}=-0.14)$.

The 538 participants $(8.6 \%)$ with emphysema on CT were slightly older, included a larger proportion of smokers, were more likely to have a prior diagnosis of emphysema or asthma and demonstrated a lower $\mathrm{FEV}_{1} / \mathrm{FVC}$ ratio (table 1).

\section{Mortality attributed to lung disease}

Telephone follow-up was completed for $96.2 \%$ of participants; deaths of participants lost to follow-up were obtained via NDI, hence vital status was known for $100 \%$.

There were 1091 deaths among 6784 participants over a median of 12 years of observation, corresponding to a mortality rate of 132 per 10000 person-years. Underlying cause of death was defined for $89 \%$ and attributed to diseases of the respiratory system or lung cancer in 77 and 95 cases, respectively, making lung disease the third leading cause of death, following circulatory diseases and non-lung (eg, breast, colon) cancers (figure 1).

Half (51\%) of respiratory disease mortality was attributed to CLRD, followed by pneumonia (31\%) and ILD (18\%) (see online supplementary table E1).

\section{Emphysema and lung disease mortality}

Cumulative incidence of mortality due to respiratory disease and lung cancer was significantly higher among persons with emphysema on CT (log-rank $\mathrm{p}<0.001$, figure 2$)$.

Emphysema on CT conferred an almost threefold increased risk of respiratory disease mortality in adjusted models (table 2, see online supplementary table E2).
Table 1 Baseline characteristics of participants in the Multi-Ethnic Study of Atherosclerosis, by presence of emphysema on CT, 20002002

\begin{tabular}{|c|c|c|}
\hline & \multicolumn{2}{|c|}{ Emphysema on CT } \\
\hline & Absent & Present \\
\hline Number of participants & 6233 & 538 \\
\hline Age, years & $62.1(10.3)$ & $63.1(10.0)$ \\
\hline Males & $2902(47 \%)$ & $290(54 \%)$ \\
\hline \multicolumn{3}{|l|}{ Race } \\
\hline White & $2365(38 \%)$ & $241(45 \%)$ \\
\hline African-American & $1703(27 \%)$ & $169(31 \%)$ \\
\hline Hispanic/Latino & $1407(23 \%)$ & $83(15 \%)$ \\
\hline Asian & $758(12 \%)$ & $45(8 \%)$ \\
\hline \multicolumn{3}{|l|}{ Smoking status } \\
\hline Never & $2915(47 \%)$ & $157(29 \%)$ \\
\hline Former & $2459(39 \%)$ & $287(53 \%)$ \\
\hline Current & $859(14 \%)$ & $94(17 \%)$ \\
\hline Pack-years & $14(3,32)$ & $19(6,42)$ \\
\hline Body mass index, $\mathrm{kg} / \mathrm{m}^{2}$ & $28.2(5.3)$ & $29.9(7.3)$ \\
\hline \multicolumn{3}{|l|}{ Education } \\
\hline Less than high school & $1147(18 \%)$ & $75(14 \%)$ \\
\hline High school & $1139(18 \%)$ & $95(18 \%)$ \\
\hline Some college but no degree & $1003(16 \%)$ & $102(19 \%)$ \\
\hline Associate/technical degree & $770(12 \%)$ & $53(10 \%)$ \\
\hline Bachelor's degree & $1062(17 \%)$ & $107(20 \%)$ \\
\hline Graduate degree & $1112(18 \%)$ & $106(20 \%)$ \\
\hline \multicolumn{3}{|l|}{ Site } \\
\hline Forsyth County, North Carolina & $994(16 \%)$ & $75(14 \%)$ \\
\hline $\begin{array}{l}\text { Upper Manhattan and the Bronx, } \\
\text { New York }\end{array}$ & $1014(16 \%)$ & $86(16 \%)$ \\
\hline Baltimore County, Maryland & $929(15 \%)$ & $133(25 \%)$ \\
\hline Minneapolis, Minnesota & $963(15 \%)$ & $99(18 \%)$ \\
\hline Chicago, Illinois & $1074(17 \%)$ & $88(16 \%)$ \\
\hline Los Angeles County, California & $1259(20 \%)$ & $57(11 \%)$ \\
\hline Physician diagnosis of emphysema & $69(1 \%)$ & $34(6 \%)$ \\
\hline Physician diagnosis of asthma & $561(9 \%)$ & $99(18 \%)$ \\
\hline \multicolumn{3}{|l|}{ Prebronchodilator airflow measures } \\
\hline $\mathrm{FEV}_{1}, \mathrm{~L}$ & $2.38(0.72)$ & $2.38(0.86)$ \\
\hline $\mathrm{FEV}_{1} / \mathrm{FVC}$ & $0.76(0.08)$ & $0.68(0.13)$ \\
\hline Restrictive ventilatory defect & $309(9 \%)$ & $12(4 \%)$ \\
\hline Agatston score & $0(0,82)$ & $11(0,149)$ \\
\hline Per cent emphysema & $2.6(1.1,4.8)$ & $12.2(8.9,15.7)$ \\
\hline
\end{tabular}

Emphysema on CT defined as per cent emphysema greater than the upper limit of normal according to reference equations. Data are $n, n / N(\%)$, mean (SD) or median (IQR). Percentages may not sum to $100 \%$ due to rounding.

Airflow obstruction defined as $\mathrm{FEV}_{1} / \mathrm{FVC}<0.7$. Pack-years enumerated among ever-smokers only. Prebronchodilator airflow measures are calculated only among the 3830 participants who underwent spirometry in 2004-2006. For 13 participants with current smoking, reference equations for the upper limit of normal could not be calculated due to missing smoking intensity data; nonetheless, these participants were included in analyses using the exposure of continuous per cent emphysema.

This association was driven by the subset of CLRD deaths, for which there was an almost 10 -fold higher risk. This association was unchanged after exclusion of seven CLRD deaths with missing $(\mathrm{N}=6)$ or ambiguous $(\mathrm{N}=1)$ records. Conversely, emphysema on CT demonstrated non-significant inverse associations with non-CLRD respiratory disease mortality. With respect to lung cancer, emphysema on CT was associated with an almost twofold increase in risk. Overall, emphysema on CT was associated with an adjusted HR of 2.25 (95\% CI 1.54 to 3.30) for the combined end point of death due to all lung diseases. 


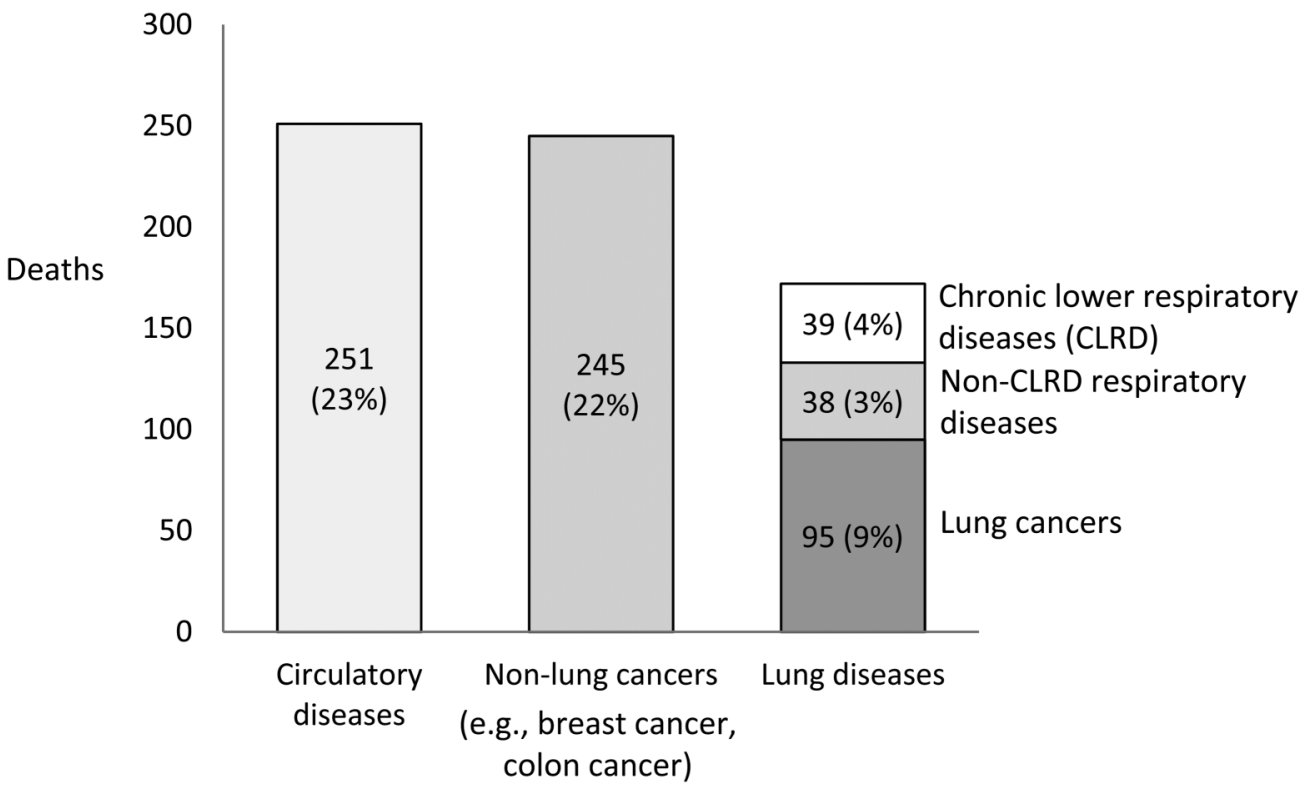

Figure 1 Top three leading causes of death in the Multi-Ethnic Study of Atherosclerosis (MESA), 2000-2013.

Results were similar after additional adjustment (see online supplementary table E2, supplementary figure E2), in models specifying survival time as time since enrolment and for upperlobe and basilar emphysema (see online supplementary table E3).

\section{Subgroup analyses}

Multiplicative interaction terms with smoking status and packyears did not attain statistical significance $(p>0.25)$. In adjusted models, the risks of lung disease mortality associated with a one IQR increase in per cent emphysema were 1.23 (95\% CI 1.03 to 1.48 ) and 1.36 (95\% CI 1.23 to 1.50 ) in persons with less than and more than 10 pack-years, respectively. Analyses restricted to never-smokers-among whom the lung disease mortality rate was markedly lower-were imprecise: emphysema on CT was associated with an approximate doubling of lung disease mortality (see online supplementary figure E2), yet effect estimates per IQR of per cent emphysema were lower, and none of these associations attained statistical significance (figure 3, see online supplementary figure E2; supplementary table E4). In ever-smokers with less than 10 pack-years,

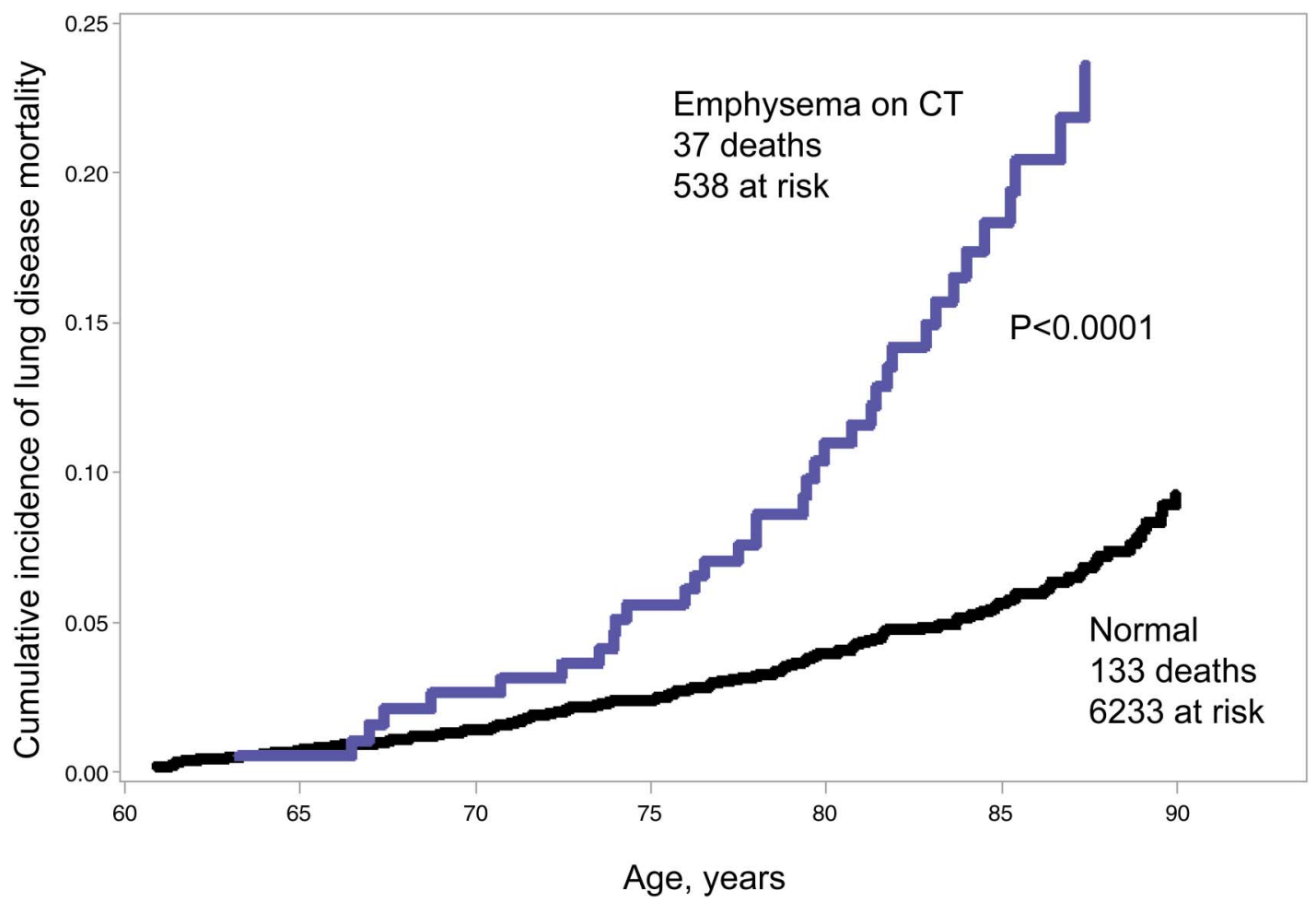

Figure 2 Cumulative incidence of mortality due to lung diseases according to presence or absence of emphysema on CT over 12 years of follow-up in the Multi-Ethnic Study of Atherosclerosis (MESA), 2000-2013. 
Table 2 Associations between emphysema on CT, per cent emphysema, and mortality due to lung disease in the Multi-Ethnic Study of Atherosclerosis, 2000-2013

\begin{tabular}{|c|c|c|c|c|c|}
\hline \multirow[b]{2}{*}{ Underlying cause of death } & \multicolumn{3}{|c|}{ Emphysema on CT (dichotomous) } & \multicolumn{2}{|c|}{ Per cent emphysema (continuous) } \\
\hline & Absent $(\mathrm{N}=6233)$ & Present $(\mathrm{N}=538)$ & p Value & All $(\mathrm{N}=6784)$ & p Value \\
\hline \multicolumn{6}{|l|}{ Respiratory diseases } \\
\hline Deaths & 57 & 18 & & 77 & \\
\hline Person-years & 71845 & 6078 & & 77750 & \\
\hline Mortality rate per 10000 person-years & 7.9 & 29.6 & & 9.9 & \\
\hline $\mathrm{HR}_{\text {crude }}(95 \% \mathrm{CI})$ & 1.00 (referent) & $3.67(2.16-6.25)$ & $<0.001$ & $1.48(1.35-1.63)$ & $<0.001$ \\
\hline $\mathrm{HR}_{\text {adjusted }}(95 \% \mathrm{Cl})$ & 1.00 (referent) & $2.94(1.68-5.15)$ & $<0.001$ & $1.51(1.35-1.69)$ & $<0.001$ \\
\hline \multicolumn{6}{|l|}{ CLRD } \\
\hline Deaths & 20 & 17 & & 39 & \\
\hline Person-years & 71845 & 6078 & & 77750 & \\
\hline Mortality rate per 10000 person-years & 2.8 & 28.0 & & 5.0 & \\
\hline $\mathrm{HR}_{\text {crude }}(95 \% \mathrm{CI})$ & 1.00 (referent) & $10.11(5.25-19.46)$ & $<0.001$ & $1.71(1.55-1.88)$ & $<0.001$ \\
\hline HR $_{\text {adjusted }}(95 \% \mathrm{CI})$ & 1.00 (referent) & $9.54(4.70-19.35)$ & $<0.001$ & $1.78(1.57-2.03)$ & $<0.001$ \\
\hline \multicolumn{6}{|l|}{ Lung cancer } \\
\hline Deaths & 76 & 19 & & 95 & \\
\hline Person-years & 71845 & 6078 & & 77750 & \\
\hline Mortality rate per 10000 person-years & 10.6 & 31.3 & & 12.2 & \\
\hline $\mathrm{HR}_{\text {crude }}(95 \% \mathrm{Cl})$ & 1.00 (referent) & $2.81(1.70-4.65)$ & $<0.001$ & $1.35(1.20-1.52)$ & $<0.001$ \\
\hline $\mathrm{HR}_{\text {adjusted }}(95 \% \mathrm{Cl})$ & 1.00 (referent) & $1.84(1.09-3.12)$ & 0.023 & $1.21(1.06-1.38)$ & 0.006 \\
\hline \multicolumn{6}{|l|}{ All lung diseases } \\
\hline Deaths & 133 & 37 & & 172 & \\
\hline Person-years & 71845 & 6078 & & 77750 & \\
\hline Mortality rate per 10000 person-years & 18.5 & 60.9 & & 22.1 & \\
\hline $\mathrm{HR}_{\text {crude }}(95 \% \mathrm{CI})$ & 1.00 (referent) & $3.16(2.20-4.56)$ & $<0.001$ & $1.42(1.32-1.53)$ & $<0.001$ \\
\hline $\mathrm{HR}_{\text {adjusted }}(95 \% \mathrm{Cl})$ & 1.00 (referent) & $2.25(1.54-3.30)$ & $<0.001$ & $1.34(1.23-1.46)$ & $<0.001$ \\
\hline \multicolumn{6}{|c|}{$\begin{array}{l}\text { The end points were defined by an underlying cause of death of respiratory disease (J00-J99), lung cancer (C33-C34) and, combining these, all lung disease. We also specifically } \\
\text { examined mortality due to CLRD (J40-47), which was defined as deaths with COPD, emphysema, chronic bronchitis or asthma as the underlying cause, or, in the context of pneumonia } \\
\text { as the underlying cause (J12-18), with these diseases (J40-47) recorded as a contributing cause. } \\
\text { For per cent emphysema, HRs reported per IQR (4.5\%), which is equivalent to the difference between the third quartile (5.7\%) and the first quartile (1.2\%) of per cent emphysema. } \\
\text { Models adjusted for baseline age, sex, race/ethnicity, body mass index, site, smoking status, pack-years of smoking, coronary artery calcium score and educational attainment. Upper } \\
\text { limit of normal for per cent emphysema defined by reference equations. } \\
\text { CLRD, chronic lower respiratory disease. }\end{array}$} \\
\hline
\end{tabular}

statistically significant associations were similar to those observed in persons with 10 or more pack-years.

Exclusion of participants with physician-diagnosed emphysema $(\mathrm{N}=104)$ or asthma $(\mathrm{N}=622)$ at baseline only slightly attenuated results, which mainly retained statistical significance (see online supplementary table E5).

Figure 3 Emphysema on CT and mortality due to lung diseases, stratified by smoking history. CLRD, chronic lower respiratory disease.

Never smokers
Models incorporating spirometry measures required restriction to persons with valid spirometry at 4 years following study entry, reducing the sample to 3835 participants and decreasing person-years of observation by $61 \%$. The fully adjusted model yielded similar effect estimates as in the main analysis, although with wider CIs (see online supplementary table E6). Further

Adjusted hazard ratio for a one IQR increase

Respiratory diseases

CLRD

Lung cancers

All lung diseases

0-10 pack-year smokers Respiratory diseases

CLRD

Lung cancers

All lung diseases

$10+$ pack-year smokers Respiratory diseases CLRD

Lung cancers

All lung diseases
At Risk Deaths in percent emphysema with $95 \% \mathrm{Cl}$

3072

3072

3072

3072

\section{4}

1494

1494

1494

13
8
7
20

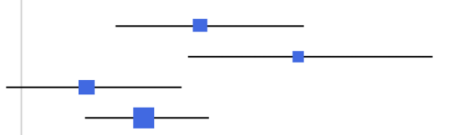

$\begin{array}{rr}2218 & 43 \\ 2218 & 26 \\ 2218 & 71 \\ 2218 & 114\end{array}$

2218

$$
\begin{array}{r}
21 \\
5 \\
17 \\
38
\end{array}
$$

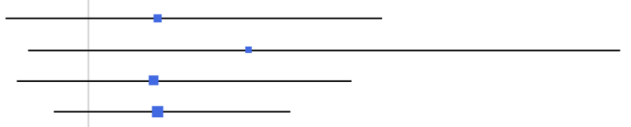


adjustment for airflow parameters did not substantially change effect estimates, but the adjusted results were not statistically significant unless they were additionally adjusted for HAA (see online supplementary tables E2 and E6).

There was no consistent evidence for effect measure modification by presence or absence of airflow limitation (table 3 ). Multiplicative interaction terms were not statistically significant. In stratified analyses, point estimates were particularly similar for respiratory disease mortality, but CIs were wide and overlapping for all end points. Extended models adjusting for spirometry measures and HAA yielded statistically significant associations in persons both with and without airflow limitation.

\section{Emphysema and other major causes of death}

Per cent emphysema was not significantly associated with circulatory disease mortality, whether this was ICD-defined (adjusted HR $1.00,95 \%$ CI 0.88 to 1.14 ) or adjudicated (adjusted HRs $1.03-1.11, \mathrm{p}>0.25$; see online supplementary table E7). The association between emphysema on CT and lung disease mortality was not attenuated in competing risk regression (HR 3.31, $95 \%$ CI 2.30 to 4.77$)$.

\section{DISCUSSION}

Emphysema on CT was associated with a twofold increase in mortality due to respiratory diseases and lung cancer in a large, population-based, multiethnic cohort. The increase in mortality risk was specific to lung diseases, particularly CLRD, without evidence for increased mortality due to cardiovascular disease and non-lung cancers. These associations did not differ consistently across smoking strata, and persisted among ever-smokers with less than 10 pack-years of smoking. Associations were similar after adjustment for airflow measures and in persons without airflow limitation. These findings suggest that emphysematous changes may be clinically relevant among persons not traditionally considered at high risk of mortality due to CLRD or lung cancer.

The prognostic significance of emphysema on CT has been mainly explored in high-risk smokers undergoing lung cancer screening and persons with $\alpha-1$ antitrypsin deficiency, among whom emphysema has been linked to all-cause and COPD mortality, independent of airflow limitation. ${ }^{2} 7$ 28-30 Studies of emphysema remain infrequent in persons without substantial smoking or COPD, among whom historical pathological series and contemporary chest CT audits have shown emphysema to be relatively common. ${ }^{1} 2431$ Smoking histories and spirometry were not available in a recent study of persons undergoing chest CT for non-pulmonary indications, which showed that radiologist-scored emphysema was specifically associated with increased mortality rates from COPD. ${ }^{32}$ In a lung cancer screening cohort, visually assessed emphysema was associated with the same increase in lung cancer risk in both never-smokers and smokers. ${ }^{33}$ MESA is one of the few resources available to study the prognostic significance of quantitative CT measures in persons without COPD or heavy smoking histories. In MESA, quantitatively assessed per cent emphysema has been associated with incident dyspnoea and hospitalisation for COPD, independent of airflow measures. ${ }^{34} 35$ Furthermore, we recently demonstrated that per cent emphysema was associated with allcause mortality among persons without airflow obstruction on spirometry. ${ }^{18}$ The present study builds upon this prior work by leveraging additional accrual of events in the cohort to examine associations between per cent emphysema and cause-specific mortality, including in 'low-risk' subgroups.
Our results demonstrate strong associations between per cent emphysema and lung disease mortality that did not differ consistently across strata of smoking, clinical disease or airflow limitation, and there was no statistical evidence for effect measure modification by these factors. In ever-smokers with less than 10 pack-years, statistically significant associations were of similar magnitude as among heavy smokers. In never-smokers, associations for per cent emphysema were attenuated compared with ever-smokers, yet the presence of emphysema on CT was associated with a doubling of lung disease mortality; however, event rates in never-smokers were less than half of those in smokers, and results did not attain statistical significance. In the context of a modest number of events, we were also unable to confirm that associations between emphysema on CT and lung disease mortality were independent of airflow measures, but effect estimates were only modestly attenuated after adjustment. In persons without airflow limitation, effect estimates were similar and attained statistical significance with additional adjustment for airflow measures and HAA, a potential radiologic confounder. Hence, longer follow-up may be required to confirm associations, but the cautious interpretation is that emphysema is a potential risk factor for lung disease mortality, even in persons without substantial smoking history or spirometrically defined COPD.

The strong associations demonstrated between quantitatively assessed emphysema and lung cancer contrast with some prior literature, which paradoxically found inverse associations, even though visually assessed emphysema has shown consistent direct associations with lung cancer. ${ }^{14}$ One explanation has been that visually assessed emphysema was superior for detecting centrilobular emphysema (CLE), ${ }^{36}$ which is mainly smoking-related, ${ }^{10}$ whereas quantitatively assessed emphysema may preferentially detect panlobular emphysema (PLE), which is equally common in smokers and never-smokers. ${ }^{14}$ In MESA, per cent emphysema as a measure of PLE is supported by associations with gene variants relating to $\alpha-1$ antitrypsin ${ }^{37}$ and measurement on cardiac CT, which excludes the major apical location of CLE. Our findings in participants with less than 10 pack-years-as well as robust associations for lower-lobe emphysema, where PLE is predominantly located-may suggest that PLE is an important prognostic factor for both respiratory disease and lung cancer mortality, even in the absence of smoking-related CLE.

Emphysema may contribute to lung disease mortality via several mechanisms. Loss of lung parenchyma and vasculature reduces area for gas exchange and results in untethering of airways, contributing to hypoxaemia and airflow obstruction. ${ }^{38}$ Obstruction may be intermittent, for example only during respiratory infection, for which emphysema may increase susceptibility. ${ }^{39}$ Emphysema also reduces cardiac output. ${ }^{40}$ Altogether, these effects of emphysema may result in poor exercise capacity and reduced functional status. ${ }^{41}$ Lung cancer may be increased in the presence of emphysema due to shared causes, such as smoking, enzymatic imbalances and inflammatory responses hypothesised to cause both emphysema and tumorigenesis. $^{42}$ Emphysema may also lead to scarring and repair processes that directly result in cancer.

There was no increased cardiovascular mortality risk related to emphysema on CT. The fact that MESA excluded persons with clinical cardiovascular disease at baseline is unlikely to account for this finding, as cardiovascular mortality was still frequent, and prior work has demonstrated that both standard and novel risk factors predict cardiovascular events in this cohort. ${ }^{27}$ Our results are consistent with the lack of association of per cent emphysema with coronary artery calcium in this cohort, ${ }^{43}$ 
Table 3 Associations between per cent emphysema and mortality due to lung disease in the Multi-Ethnic Study of Atherosclerosis, stratified by airflow limitation, 2004-2013

\begin{tabular}{|c|c|c|c|c|c|}
\hline \multirow[b]{2}{*}{ Underlying cause of death } & \multicolumn{4}{|c|}{ Per cent emphysema as continuous exposure in persons with valid spirometry measures } & \multirow{2}{*}{$\begin{array}{l}p \text { Interaction for } \\
\text { airflow limitation }\end{array}$} \\
\hline & Airflow limitation $(\mathrm{N}=863)$ & p Value & No airflow limitation ( $N=2965)$ & p Value & \\
\hline \multicolumn{6}{|l|}{ Respiratory diseases } \\
\hline Deaths & 8 & & 12 & & 0.597 \\
\hline Person-years & 6418 & & 22843 & & \\
\hline Mortality rate per 10000 person-years & 12.5 & & 5.3 & & \\
\hline \multicolumn{6}{|l|}{$\mathrm{HR}(95 \% \mathrm{Cl})$} \\
\hline $\mathrm{HR}_{\text {crude }}(95 \% \mathrm{Cl})$ & $1.38(0.87$ to 2.19$)$ & 0.171 & $1.41(0.79$ to 2.50$)$ & 0.244 & \\
\hline $\mathrm{HR}_{\text {adjusted }}(95 \% \mathrm{Cl})$ & $1.32(0.98$ to 1.78$)$ & 0.069 & $1.30(0.58$ to 2.94$)$ & 0.525 & \\
\hline$H R_{\text {extended }}(95 \% \mathrm{Cl})$ & $1.40(1.02$ to 1.93$)$ & 0.038 & $2.38(1.01$ to 5.60$)$ & 0.047 & \\
\hline \multicolumn{6}{|l|}{ Lung cancer } \\
\hline Deaths & 18 & & 18 & & 0.593 \\
\hline Person-years & 6418 & & 22843 & & \\
\hline Mortality rate per 10000 person-years & 28.1 & & 7.9 & & \\
\hline \multicolumn{6}{|l|}{$\mathrm{HR}(95 \% \mathrm{Cl})$} \\
\hline $\mathrm{HR}_{\text {crude }}(95 \% \mathrm{Cl})$ & 1.39 (1.03 to 1.88$)$ & 0.031 & $1.03(0.58$ to 1.85$)$ & 0.920 & \\
\hline $\mathrm{HR}_{\text {adjusted }}(95 \% \mathrm{Cl})$ & $1.31(0.89$ to 1.93$)$ & 0.170 & 1.14 (0.58 to 2.24$)$ & 0.709 & \\
\hline $\mathrm{HR}_{\text {extended }}(95 \% \mathrm{CI})$ & 1.52 (1.01 to 2.28$)$ & 0.046 & $1.56(0.82$ to 2.96$)$ & 0.172 & \\
\hline \multicolumn{6}{|l|}{ All lung diseases } \\
\hline Deaths & 26 & & 30 & & 0.930 \\
\hline Person-years & 6418 & & 22843 & & \\
\hline Mortality rate per 10000 person-years & 40.5 & & 13.1 & & \\
\hline \multicolumn{6}{|l|}{$\mathrm{HR}(95 \% \mathrm{Cl})$} \\
\hline $\mathrm{HR}_{\text {crude }}(95 \% \mathrm{Cl})$ & 1.39 (1.08 to 1.78$)$ & 0.011 & $1.18(0.79$ to 1.78$)$ & 0.413 & \\
\hline $\mathrm{HR}_{\text {adjusted }}(95 \% \mathrm{Cl})$ & 1.32 (0.98 to 1.78$)$ & 0.071 & $1.16(0.71$ to 1.90$)$ & 0.542 & \\
\hline $\mathrm{HR}_{\text {extended }}(95 \% \mathrm{CI})$ & $1.38(1.01$ to 1.90$)$ & 0.044 & $1.63(1.02$ to 2.61$)$ & 0.043 & \\
\hline
\end{tabular}

yet seemingly inconsistent with extensive prior work demonstrating high rates of comorbidity and cardiovascular mortality in COPD, ${ }^{44}$ and associations between cardiovascular outcomes and smoking, the major risk factor for emphysema. Therefore, our data suggest that per cent emphysema on CT is not merely a radiologic correlate of smoking exposure or airflow obstruction; further support for this includes limited correlations between per cent emphysema and spirometric measures, only modest attenuation of associations after adjustment for spirometry and persistence of associations among persons without clinical CLRD.

Since per cent emphysema was shown not to be significantly associated with other leading causes of death in MESA, associations with lung disease mortality are unlikely to be substantially biased by informative censoring or competing risks effects. Results were essentially unchanged in competing risks regression.

There are nonetheless several limitations that should be considered. Per cent emphysema was calculated from cardiac CT scans, which did not include the apices, yet these measures show high correlation with measures from full-lung scans in MESA. ${ }^{23}$ We defined emphysema on CT based upon reference equations derived from healthy never-smokers in MESA to account for known differences in per cent emphysema by age, sex, race/ethnicity and body size, using an approach similar to the one used for spirometry. ${ }^{24} 45$ While this approach is valid within the cohort and consistent with ATS/ERS recommendations, it limits generalisation: MESA reference equations for per cent emphysema on full-lung scans are likely to apply in cohorts using the same CT protocol, yet there is no evidence to date that they apply in cohorts or clinical practice using different protocols.

Cause of death was defined by administrative coding, which has the potential for both overdiagnosis and underdiagnosis. ${ }^{46}$ Standardised protocols for adjudicating CLRD events are lacking, and validation studies for ICD-coded COPD end points have generally used spirometric airflow obstruction as the reference standard, even though this is frequently absent in emphysema, chronic bronchitis and asthma. We performed independent two-physician review of available records for CLRD deaths to confirm the underlying cause of death, and found that censoring of the small number of ambiguous or unavailable records did not alter results. Neither participants nor their physicians were informed regarding results for per cent emphysema on study CTs, avoiding diagnostic suspicion bias. Since we ascertained mortality rather than incidence, participants with non-fatal pulmonary outcomes, such as CLRD exacerbations, might be analysed as censored with respect to lung disease mortality if they were still alive or if they died from a competing cause. However, limiting end points according to underlying cause of death was intended to minimise falsepositive misclassification, which is more likely to introduce bias than false negatives. ${ }^{47}$

Spirometry was only available for a subset, was acquired after baseline and hence at a different time than CT and other covariate measures and did not include postbronchodilator measures. Restricting to persons without airflow limitation on 
prebronchodilator spirometry conservatively excludes COPD, but follow-up and events in this subgroup were limited.

Modest event rates for CLRD mortality and in never-smoking and no-airflow-limitation subgroups limited the precision and stability of results in related analyses, and the number of subanalyses could raise concern for type I error. Nonetheless, the high level of statistical significance for our main findings, buttressed by their consistency in sequentially adjusted and subgroup analyses, as well as with the prior literature in high-risk samples, supports the interpretation that emphysema is associated with elevated risk of lung disease mortality in the general population.

In conclusion, emphysema on CT was strongly associated with increased respiratory and lung cancer mortality in a multiethnic population-based sample. Results persisted among participants without substantial smoking histories or clinical disease, and were similar in persons without airflow limitation. From a clinical standpoint, these findings suggest that emphysema on CT is not a benign incidental finding. Even in never-smokers or lightsmokers, detection of emphysema on chest radiography should prompt physicians to review potentially modifiable risk factors for lung disease mortality and to consider spirometry testing and, if indicated, medical therapy for COPD. Further investigation into mechanisms of and specific therapies for emphysema detected on $\mathrm{CT}$ is warranted.

\author{
Author affiliations \\ 1 Department of Medicine, Columbia University Medical Center, New York, \\ New York, USA \\ ${ }^{2}$ Department of Epidemiology, Mailman School of Public Health at Columbia \\ University, New York, New York, USA \\ ${ }^{3}$ Department of Radiology, Vanderbilt University Medical Center, Nashville, \\ Tennessee, USA \\ ${ }^{4}$ Department of Medicine, University of Arizona, Tuscon, Arizona, USA \\ ${ }^{5}$ Department of Radiology, University of lowa, lowa City, lowa, USA \\ ${ }^{6}$ Division of Epidemiology and Community Health, University of Minnesota, \\ Minneapolis, Minnesota, USA \\ ${ }^{7}$ Department of Medicine, University of Pennsylvania, Philadelphia, Pennsylvania, \\ USA \\ ${ }^{8}$ Collaborative Health Studies Coordinating Center, University of Washington, Seattle, \\ Washington, USA \\ ${ }^{9}$ Department of Medicine, Johns Hopkins University, Baltimore, Maryland, USA \\ ${ }^{10}$ Respiratory Division, McGill University, Montreal, Quebec, Canada
}

\section{Twitter Follow David Lederer at @ davidlederer}

Acknowledgements MESA is supported by the National Heart, Lung, and Blood Institute (NHLBI) and was designed and conducted by the MESA investigators in collaboration with NHLBI staff. The information contained herein was derived in part from data provided by the Bureau of Vital Statistics, New York City Department of Health and Mental Hygiene. NHLBI staff routinely monitored study performance and participated in the internal review of this manuscript prior to submission. The authors thank the other investigators, the staff and the participants of the MESA study for their valuable contributions. A full list of participating MESA investigators and institutions can be found at http://www.mesa-nhlbi.org.

Contributors ECO was primarily responsible for data analysis and drafting of the manuscript, and vouches for the integrity of the data and analyses presented. All authors were involved in the conception, design and drafting of the manuscript for important intellectual content, and all have approved the final manuscript.

Funding NIH/NHLBI R01-HL077612, RC1-100543, N01-HC-95159 through N01-HC-95169, UL1-TR000040 and R21-HL129924.

Competing interests EAH is a founder and shareholder of VIDA Diagnostics, a company commercialising lung imaging analysis software developed, in part, at the University of lowa. He is also a non-paid member of Siemens Medical Imaging CT advisory board. DJL reports serving as a consultant to Gilead, Intermune, Boehinger-Ingelheim, Immuneworks and XVIVO therapeutics related to clinical trials in interstitial pulmonary fibrosis and lung transplantation. SMK reports personal fees from Insmed, non-financial support from American College of Chest Physicians, non-financial support from American Thoracic Society, personal fees from European Respiratory Journal, grants from Actelion, grants from United Therapeutics, grants from Gilead, grants from Lung Biotech, grants from Pfizer, grants from Ikaria, grants from Pulmonary Hypertension Association, grants from Actelion, grants from Gilead, grants from Merck, grants from GeNO, grants from Bayer, all outside the submitted work. JACL reports grants from Toshiba Medical Systems, outside the submitted work. RGB reports personal fees from UpToDate, non-financial support from COPD Foundation, both outside the submitted work.

Ethics approval The study was approved by the National Heart, Lung and Blood Institute as well as institutional review boards of all collaborating institutions. All participants gave written informed consent.

Provenance and peer review Not commissioned; externally peer reviewed.

\section{REFERENCES}

1 Aberle DR, Adams AM, Berg CD, et al. Reduced lung-cancer mortality with low-dose computed tomographic screening. N Engl J Med 2011;365:395-409.

2 Zulueta JJ, Wisnivesky JP, Henschke $\mathrm{Cl}$, et al. Emphysema scores predict death from COPD and lung cancer. Chest 2012;141:1216-23.

3 Tsushima K, Sone S, Fujimoto K, et al. Identification of occult parenchymal disease such as emphysema or airway disease using screening computed tomography. COPD 2010;7:117-25.

4 Burt JR, Iribarren C, Fair JM, et al. Incidental findings on cardiac multidetector row computed tomography among healthy older adults: prevalence and clinical correlates. Arch Intern Med 2008;168:756-61.

5 Decramer M, Janssens W, Miravitlles M. Chronic obstructive pulmonary disease. Lancet 2012;379:1341-51

6 Vestbo J, Hurd SS, Agustí AG, et al. Global strategy for the diagnosis, management, and prevention of chronic obstructive pulmonary disease: GOLD executive summary. Am J Respir Crit Care Med 2013;187:347-65.

7 Johannessen A, Skorge TD, Bottai M, et al. Mortality by level of emphysema and airway wall thickness. Am J Respir Crit Care Med 2013;187:602-8.

8 Regan EA, Lynch DA, Curran-Everett D, et al. Clinical and radiologic disease in smokers with normal spirometry. JAMA Intern Med 2015;175:1539-49.

9 Marsh SE, Travers J, Weatherall M, et al. Proportional classifications of COPD phenotypes. Thorax 2008;63:761-7.

10 Anderson AE Jr, Hernandez JA, Eckert P, et al. Emphysema in lung macrosections correlated with smoking habits. Science 1964;144:1025-6.

11 Sanchez-Salcedo P, Wilson DO, de-Torres JP, et al. Improving selection criteria for lung cancer screening. The potential role of emphysema. Am I Respir Crit Care Med 2015;191:924-31.

12 de-Torres JP, Wilson DO, Sanchez-Salcedo P, et al. Lung cancer in patients with chronic obstructive pulmonary disease. Development and validation of the COPD Lung Cancer Screening Score. Am J Respir Crit Care Med 2015;191:285-91.

13 McWilliams A, Tammemagi MC, Mayo JR, et al. Probability of cancer in pulmonary nodules detected on first screening CT. N Engl J Med 2013;369:910-19.

14 Smith BM, Pinto L, Ezer N, et al. Emphysema detected on computed tomography and risk of lung cancer: a systematic review and meta-analysis. Lung Cancer 2012;77:58-63.

15 Centers for Disease Control. National Health and Nutrition Examination Survey Data, 2009-10. Hyattsville, MD: National Center for Health Statistics, 2001.

16 Jamal A, Homa DM, O'Connor E, et al. Current cigarette smoking among adultsUnited States, 2005-2014. MMWR Morb Mortal Wkly Rep 2015;64:1233-40.

17 Navas-Nacher EL, Kelley MA, Birnbaum-Weitzman O, et al. Association between exposure to household cigarette smoking behavior and cigarette smoking in Hispanic adults: Findings from the Hispanic Community Health Study/Study of Latinos. Prev Med 2015;77:35-40.

18 Oelsner EC, Hoffman EA, Folsom AR, et al. Association between emphysema-like lung on cardiac computed tomography and mortality in persons without airflow obstruction: a cohort study. Ann Intern Med 2014;161:863-73.

19 Bild DE, Bluemke DA, Burke GL, et al. Multi-Ethnic Study of Atherosclerosis: objectives and design. Am J Epidemiol 2002;156:871-81.

20 World Health Organization. International Classification of Diseases. 10th edn. Geneva: WHO, 2010.

21 Ford ES, Croft JB, Mannino DM, et al. COPD surveillance-United States, 19992011. Chest 2013;144:284-305.

22 Carr JJ, Nelson JC, Wong ND, et al. Calcified coronary artery plaque measurement with cardiac CT in population-based studies: standardized protocol of Multi-Ethnic Study of Atherosclerosis (MESA) and Coronary Artery Risk Development in Young Adults (CARDIA) study. Radiology 2005;234:35-43.

23 Hoffman EA, Jiang $R$, Baumhauer $H$, et al. Reproducibility and validity of lung density measures from cardiac CT Scans-The Multi-Ethnic Study of Atherosclerosis (MESA) Lung Study. Acad Radiol 2009;16:689-99.

24 Hoffman EA, Ahmed FS, Baumhauer $\mathrm{H}$, et al. Variation in the percent of emphysema-like lung in a healthy, nonsmoking multiethnic sample. The MESA lung study. Ann Am Thorac Soc 2014;11:898-907.

25 Lederer DJ, Enright PL, Kawut SM, et al. Cigarette smoking is associated with subclinical parenchymal lung disease: the Multi-Ethnic Study of Atherosclerosis (MESA)-lung study. Am J Respir Crit Care Med 2009;180:407-14.

26 Miller MR, Hankinson J, Brusasco V, et al. Standardisation of spirometry. Eur Respir J 2005;26:319-38. 
27 Detrano R, Guerci AD, Carr JJ, et al. Coronary calcium as a predictor of coronary events in four racial or ethnic groups. N Engl J Med 2008;358:1336-45.

28 Martinez FJ, Foster G, Curtis JL, et al. Predictors of mortality in patients with emphysema and severe airflow obstruction. Am J Respir Crit Care Med 2006;173:1326-34.

29 Müllerova H, Maselli DJ, Locantore N, et al. Hospitalized exacerbations of COPD: risk factors and outcomes in the ECLIPSE cohort. Chest 2015;147:999-1007.

30 Dawkins PA, Dowson LJ, Guest PJ, et al. Predictors of mortality in alpha1-antitrypsin deficiency. Thorax 2003;58:1020-6.

31 Auerbach 0, Hammond EC, Garfinkel L, et al. Relation of smoking and age to emphysema. Whole-lung section study. N Engl J Med 1972;286:853-7.

32 Jairam PM, van der Graaf Y, Lammers JW, et al. Incidental findings on chest CT imaging are associated with increased COPD exacerbations and mortality. Thorax 2015;70:725-31.

33 Henschke $\mathrm{Cl}$, Yip R, Boffetta P, et al. CT screening for lung cancer: Importance of emphysema for never smokers and smokers. Lung Cancer 2015;88:42-7.

34 Oelsner EC, Lima JA, Kawut SM, et al. Noninvasive tests for the diagnostic evaluation of dyspnea among outpatients: the Multi-Ethnic Study of Atherosclerosis lung study. Am J Med 2015;128:171-80 e175.

35 McAllister DA, Ahmed FS, Austin JH, et al. Emphysema predicts hospitalisation and incident airflow obstruction among older smokers: a prospective cohort study. PLoS ONE 2014;9:e93221.

36 Copley SJ, Wells AU, Müller NL, et al. Thin-section CT in obstructive pulmonary disease: discriminatory value. Radiology 2002;223:812-19.

37 Manichaikul A, Hoffman EA, Smolonska J, et al. Genome-wide study of percent emphysema on computed tomography in the general population. The Multi-Ethnic
Study of Atherosclerosis Lung/SNP Health Association Resource Study. Am J Respir Crit Care Med 2014;189:408-18.

38 Saetta M, Finkelstein R, Cosio MG. Morphological and cellular basis for airflow limitation in smokers. Eur Respir J 1994;7:1505-15.

39 Beasley V, Joshi PV, Singanayagam A, et al. Lung microbiology and exacerbations in COPD. Int J COPD 2012;7:555-69.

40 Barr RG, Bluemke DA, Ahmed FS, et al. Percent emphysema, airflow obstruction, and impaired left ventricular filling. N Engl J Med 2010;362:217-27.

41 Estépar RS, Kinney GL, Black-Shinn JL, et al. Computed tomographic measures of pulmonary vascular morphology in smokers and their clinical implications. Am J Respir Crit Care Med 2013;188:231-9.

42 Sun Z, Yang P. Role of imbalance between neutrophil elastase and alpha 1-antitrypsin in cancer development and progression. Lancet Oncol 2004;5:182-90.

43 Barr RG, Ahmed FS, Carr JJ, et al. Subclinical atherosclerosis, airflow obstruction and emphysema: the MESA Lung Study. Eur Respir J 2012;39:846-54.

44 Sin DD, Anthonisen NR, Soriano JB, et al. Mortality in COPD: Role of comorbidities. Eur Respir J 2006;28:1245-57.

45 Hankinson JL, Kawut SM, Shahar E, et al. Performance of American Thoracic Society-recommended spirometry reference values in a multiethnic sample of adults: the Multi-Ethnic Study of Atherosclerosis (MESA) lung study. Chest 2010;137:138-45.

46 Jensen HH, Godtfredsen NS, Lange $P$, et al. Potential misclassification of causes of death from COPD. Eur Respir J 2006;28:781-5.

47 Barr RG, Herbstman J, Speizer FE, et al. Validation of self-reported chronic obstructive pulmonary disease in a cohort study of nurses. Am J Epidemiol 2002;155:965-71. 